\title{
O JOGO LÚDICO COMO METODOLOGIA DE ENSINO SOCIOEDUCATIVO ${ }^{1}$
}

\author{
Henrique Corrêa Lopes²; Leonardo Guedes Henn³; Taís Steffenello Ghisleni ${ }^{4}$
}

\section{Resumo}

Esse artigo tem por finalidade elucidar a utilização do jogo lúdico em uma unidade de atendimento socioeducativo que recebe em regime de internação adolescentes com delitos e infrações em cumprimento de medida socioeducativa, oportunizando dessa forma o desenvolvimento de práticas pedagógicas e educacionais voltadas para 0 desenvolvimento de raciocínio lógico, de integração e de interação entre esses adolescentes. objetivo desse texto é apresentar uma atividade desenvolvida na Escola Estadual de Ensino Médio Humberto de Campos, em anexo ao Centro de Atendimento Socioeducativo (CASE) localizado na cidade de Santa Maria-RS, escola que garante a sequência educacional, sendo essa educação obrigatória para os adolescentes internos em cumprimento de medida socioeducativa, a fim de promover o engajamento dos discentes envolvidos. Após a execução das atividades foi observada a integração dos participantes, a percepção de cada um sobre os jogos utilizados e a aceitação da proposta apresentada.

Palavras-chave: Acolhimento; Educação; Memória.

Eixo Temático: Educação, Cultura e Comunicação (ECC)

\section{INTRODUÇÃO}

O mundo e por consequência o ser humano passa pelo decorrer de sua história por constantes transformações e modificações que podem interferir e alterar a estrutura política, social e cultural, de uma sociedade. Nesse sentido, a trazendo para a abordagem desse artigo, a educação sofreu também uma transformação, ou seja, conforme comenta Gabriel (2013), o jovem estudava no final do século XX, apenas para cumprir um rito social, terminando a educação básica, e quem sabe futuramente qualificar-se em um ensino superior. Qualificação essa, que no século XXI, é constante, necessária e algumas vezes obrigatória para que o indivíduo atenda não

\footnotetext{
1 Trabalho desenvolvido para a disciplina de Seminário Integrado II do Mestrado em Ensino de Humanidades e Linguagens da Universidade Franciscana - UFN.

2 Aluno do curso de Mestrado em Ensino de Humanidades e Linguagens - Universidade Franciscana (UFN). Bolsista PROSUC CAPES. E-mail: henriquecorrealopes@gmail.com.

3 Doutor em História, docente do curso de História e Mestrado em Ensino de Humanidades e Linguagens - Universidade Franciscana - UFN, Santa Maria, RS. E-mail: Ighenn@gmail.com

${ }^{4}$ Dra. em Comunicação. Professora do Curso de Publicidade e Propaganda e do Mestrado em Ensino de Humanidades e Linguagens - Universidade Franciscana (UFN). E-mail: taisghisleni@yahoo.com.br
} 
somente as suas necessidades, mas também desenvolvam inovações, criatividades e um novo pensamento, contribuindo assim, com uma educação continuada, para a transformação social, cultural e econômica da sociedade onde vive.

Moran (2021) relata que "já sabíamos, há muito tempo, que a educação precisava mudar. Agora constatamos o tamanho do desafio que temos pela frente". 0 autor também afirma que hoje em dia já é possível aprender de várias formas e em diferentes espaços. No entanto, para que essa transformação ocorra e a aprendizagem aconteça, os indivíduos devem sair da educação tradicional, monótona e de memorização, ostensiva e disciplinadora, e buscar um ambiente inovador e que atinja seu propósito, a qualificação, e a atualização, nesse contexto, com a inserção e o auxílio das tecnologias digitais e da informação.

A separação entre espaços físicos presenciais e digitais diminuiu, se reconfigurou - como em outras áreas da nossa vida - e há um crescente consenso de que construiremos, a partir de agora, muitas propostas diferentes de ensinar e de aprender híbridas, mais flexíveis, personalizadas e participativas, de acordo com a situação, necessidades e possibilidades de cada aprendiz. As arquiteturas pedagógicas serão mais abertas, personalizadas, ativas $\mathrm{e}$ colaborativas, com diferentes combinações, arranjos, adaptações num país com realidades muito desiguais (MORAN, 2021, p.1).

Em um contexto pandêmico, as tecnologias da informação suplantaram em um primeiro momento os meios educacionais convencionais, ora presenciais, e por questões de segurança sanitária, foram estabelecidos os protocolos de distanciamento social e de proteção individual e coletiva, que alteraram também as rotinas nas unidades de atendimento socioeducativo.

Os serviços de atendimento socioeducativos atuam como instituições que garantem o cumprimento da medida socioeducativa, assegurando aos adolescentes, o respeito, a dignidade, a educação continuada, a saúde e os direitos estabelecidos através do Estatuto da Criança e do Adolescente e de seu órgão regulador.

A Fundação de Atendimento Sócio-Educativo (Fase/RS) foi criada a partir da Lei Estadual no 11.800, de 28 de maio de 2002 e do Decreto Estadual no 41.664 - Estatuto Social, de 6 de junho de 2002, consolidando o processo de reordenamento institucional iniciado com o advento do Estatuto da Criança e do Adolescente - ECA (Lei 8.069/90), o qual também provocou o fim da antiga Fundação do BemEstar do Menor (Febem) (FASE, 2021). 
Dentre as alterações na rotina dessas unidades, foram canceladas as visitas familiares, as quais são aguardadas com grande expectativa pelos adolescentes, dessa forma, a ausência da família ou de amigos, gerou no interior da unidade a instabilidade emocional dos adolescentes em regime de internação, ocorrendo a alteração de humor, irritabilidade e descontrole emocional.

Nesse contexto, foi sugerido a execução de atividades complementares, como a aplicação de jogos lúdicos, capazes de despertar o interesse dos adolescentes, enfatizar atividades e habilidades de diversão, de recreação e de desenvolvimento intelectual e cognitivo, assim para Teixeira (2018), o jogo envolve sentimentos e afetividades, os quais, muitos desses adolescentes não tiveram em sua infância.

Com base no contexto exposto, o objetivo desse texto é apresentar uma atividade desenvolvida na Escola Estadual de Ensino Médio Humberto de Campos, em anexo ao Centro de Atendimento Socioeducativo (CASE) localizado na cidade de Santa Maria-RS, escola que garante a sequência educacional, sendo essa educação obrigatória para os adolescentes internos em cumprimento de medida socioeducativa, a fim de promover o engajamento dos discentes envolvidos.

\section{EDUCAÇÃO COM O USO DE JOGOS}

"A associação entre jogos e ensino se enfatizou desde que os jogos começaram a despertar o interesse de públicos jovens cada vez mais numerosos, pois, diante de tantas telas e dispositivos digitais que atraem as gerações da cibercultura, seria difícil não tentar inserir os jogos em contextos de ensino" (KNOLL, SOARES e MOREIRA, 2021, p. 17). Os jogos são por natureza uma atividade de descontração, e que contribuem para os processos de aprendizagem, assim, destacando no homem, seu desenvolvimento de raciocínio lógico e cognitivo.

Para Knoll et. al (2021, p. 356), "os jogos aplicados ao contexto educacional podem trazer benefícios significativos para todo o processo de ensino e aprendizagem, tanto em uma atividade que utilize jogos ou jogos sérios, quanto em uma experiência mais completa de gamificação.

Alves (2014) entende gamificação como o uso de componentes de jogos (dinâmica, mecânica e estética) em contextos que não são próprios de jogos, mas que 
tem foco na criação de uma experiência de jogo para determinado fim que não seja o entretenimento. Alves (2014, p. 3), esclarece ainda que a gamificação "não é aplicável apenas com o uso de tecnologia, muito pelo contrário". A gamificação pode existir nas formas mais simples e onde menos esperamos encontrá-la.

Os jogos, sofrem alterações, transformações e aprimoramentos que acompanham a evolução humana, dessa forma, surge a vídeo dimensão, colocando o real a própria realidade, como se o jogador estivesse realmente fazendo e/ou participando de uma ação, nesse contexto, as máquinas de fliperama constituem uma evolução do jogo, ou seja, o jogo eletrônico, que mais tarde chegam as casas de muitos jovens com o nome de videogame, oferecendo muitos desafios e diversão.

A diversão é um elemento de extrema importância e faz com que tenhamos interesse e prazer em jogar. Jogamos porque é bom, por sentirmos prazer porque ao percebermos que estamos participando da construção de algo enquanto interagimos. (ALVES, 2014, p.43).

Com a inserção de jogos no ambiente de aprendizagem, também consegue-se inserir uma motivação a mais dentro do processo. Mas, vale ressaltar que "a principal aproximação entre os jogos educativos e a gamificação da aprendizagem é que ambos têm como meta específica a educação ou o ensino, ainda que um seja o artefato criado especificamente para uso educativo, e o outro seja uma experiência de jogo que motiva a aprendizagem" (KNOLL et. al. 2021, p. 357).

Por outro lado, com a utilização de jogos e plataformas eletrónicas, ocorreu a perda de ludicidade dos jogos em prol de seu caráter competitivo, diferenciando da sua essência de brincadeira e passatempo, colocando o jogo como algo mais sério ou o confronto de forças e da concepção freireana, que concentra uma pedagogia humana, educacional, motivados pela esperança, pela humanização e pelo conhecimento prévio do indivíduo.

Esse é um cenário assustador de transformações para as instituições de ensino e professores, que precisam compreender as novas regras do jogo e aprender a jogar rapidamente. Se por um lado isso parece ser uma ameaça aos professores e instituições de ensino, por outro talvez esse seja o maior salto na história da humanidade para uma revolução espetacular da educação, aprendizagem e sociedade, e, nesse contexto, o professor tem um papel fundamental (GABRIEL, 2013, p. 126). 
Entretanto, em relação às brincadeiras e aos jogos, atualmente estes estão relacionados em sua grande maioria, às tecnologias digitais e aos jogos eletrônicos, que possibilitam uma outra conexão cultural e social e assim, a criança e o adolescente estão mais dentro de suas casas do que fora.

A partir da década de 1990, as novas tecnologias foram tirando pouco a pouco as crianças das ruas perigosas para o confinamento de suas casas. A preocupação com a violência, os sequestros e as fugas abriram espaços para novos paradigmas do conceito de brincar, e a televisão tornou-se o mais novo objeto lúdico de desejo das crianças. (TEIXEIRA, 2018, p.53).

Contudo, os jogos lúdicos podem ser utilizados como procedimentos pedagógicos, desenvolvendo-se primeiramente na formação inicial, em um ambiente educacional voltado para além de sua educação formal, e depois ser um instrumento mediador de educação continuada, atingindo um caráter cultural.

A educação é responsável pela socialização, que é a possibilidade de convívio, com qualidade de vida de uma pessoa na sociedade, viabiliza, portanto, com um caráter cultural acentuado, a integração do indivíduo com o meio. A ação pedagógica conduz o indivíduo para a vida em sociedade, produzindo cultura e usufruindo-se dela. (MINETTO, 2008, p. 19-20).

Independentemente do tipo de jogo escolhido, "os jogos funcionam como tecnologia educacional ou recurso de aprendizagem, já que despertam o interesse dos estudantes, principalmente por serem produtos habitualmente divertidos e de entretenimento" (KNOLL, et. al., 2021, p. 370). Cabe aos docentes a escolha do jogo apropriado para cada contexto de ensino aprendizagem.

\section{ASPECTOS METODOLÓGICOS}

Para a aplicação da atividade que aqui está relatada, desenvolvida com alunos de um Centro de Atendimento Socioeducativo, foram utilizados alguns jogos lúdicos que tinham a capacidade de envolver todos os adolescentes. Também foi observada a característica de utilizar jogos que atendessem às regras de segurança da unidade de atendimento socioeducativo, bem como, a distribuição dos adolescentes em grupos que não ultrapassassem os limites de ocupação de cada sala de aula, ou seja, quatro integrantes. A atividade foi praticada nas aulas da quarta-feira, com os alunos 
da totalidade $6^{\mathbf{a}}$ do EJA, durante três semanas, totalizando seis períodos de 40 minutos cada um.

O objetivo da aula era aprimorar a criatividade, o raciocínio e o pensamento crítico de cada aluno, estimulando os valores humanos, como a integração, o respeito e a cooperação, além de tornar a sala de aula mais sociável e atuando como instrumento mediador nas relações humanas. A atividade está de acordo com os ensinamentos de Teixeira e Apresentação (2014, p.305) quando explicam que

\begin{abstract}
a utilização do jogo como material pedagógico tem como objetivo criar um ambiente descontraído que viabilize a aprendizagem significativa por meio da observação, da criatividade, do pensamento lógico, da resolução de situação problema, da articulação com diferentes conhecimentos e da inter-relação com os colegas de sala.
\end{abstract}

A figura 01 ilutra os jogos de tabuleiro selecionados para o desenvolvimento das atividades. São eles: banco imobiliário (A), os enigmas: desafio do T (B), o desafio tire a argola (C) e o desafio da pirâmide (D).

Figura 01: Jogos utilizados na dinâmica proposta

A

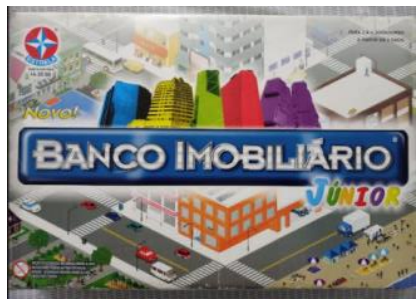

C

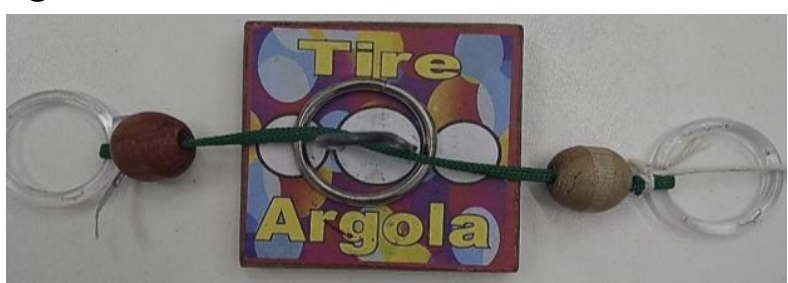

B

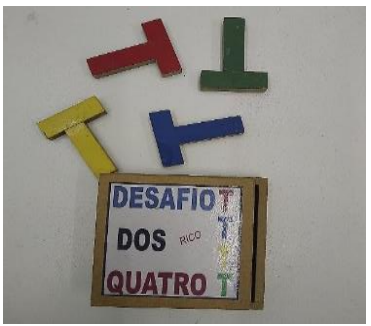

D

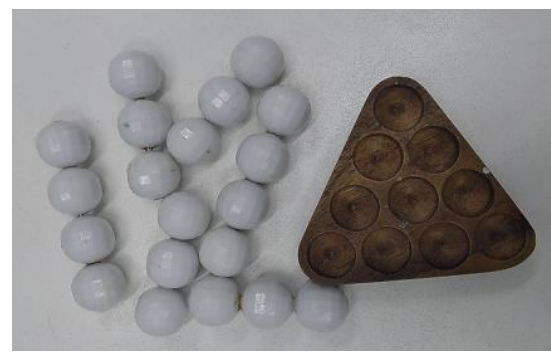

Fonte: Registro pessoal.

Para que todos pudessem entender e compreender as regras e demais demandas de cada atividade, foi realizada com a participação de outros professores, incluindo uma dinâmica ou demonstração de cada jogo lúdico, dessa forma, todos 
inclusive os professores poderiam entender o funcionamento de cada jogo, bem como, de sua resolução, um momento participativo, cooperativo e alegre.

A participação dos professores da escola foi essencial, não somente para a demonstração das atividades, mas também, como forma de auxiliar em suas práticas e metodologias pedagógicas, oferecendo uma oportunidade de trabalhar de forma lúdica com os adolescentes em internação e propiciar, conforme as práticas restaurativas, o acolhimento, a humanização desses adolescentes e sua possível socialização.

\section{RESULTADOS E DISCUSSÕES}

As atividades desenvolvidas abordaram características da educação inclusiva ${ }^{5}$, como proposta de integração entre os adolescentes e por consequência a interação que esse tipo de atividade pode originar, podendo agregar novas conversações e reflexões e do compartilhamento dessa atividade lúdica que impacta diretamente no comportamento dos adolescentes.

A inclusão necessita de ações eficazes que garantam os desenvolvimentos intelectual, social, efetivo e profissional da clientela a qual se destina. Para tanto, faz-se necessário subsidiá-lo com uma filosofia que inter-relacione as situações existentes com os ideais necessários, de modo que, qualitativamente, compreenda a diversidade nos diferentes serviços educacionais existentes, seja no ensino regular, seja no especial (GUEBERT, 2012, p.17).

Portanto, a educação inclusiva parte do pressuposto que há uma relação entre a diversidade cultural, a relação de situações vivenciadas pelos adolescentes e seu contexto social e escolar, sendo assim, esse projeto trabalha com o processo educativo do conhecimento individual e coletivo, de forma integradora, reflexiva de apresentação, estímulo e entendimento, propondo a relação entre o respeito e a inclusão.

Consideramos a inclusão como um paradigma possível, necessário e urgente, mediante a constatação da diversidade como elemento integrante da natureza humana. Porém, sua implantação esbarra a

\footnotetext{
${ }^{5} \mathrm{~A}$ educação inclusiva considera educar todas as crianças em um mesmo contexto escolar. Com a inclusão, as diferenças não são vistas como problemas, mas como diversidade.
} 
todo o momento em práticas que privilegiam a homogeneidade (ou seja, a semelhança como princípio constitutivo). Quem difere desse conjunto "homogêneo" fatalmente cairá em exclusão educacional. Para que isso não aconteça, as práticas pedagógicas devem ser diversificadas, e isso depende em grande parte da capacidade do docente (MINETTO, 2008, p.35).

As atividades propostas obtiveram resultados positivos, tanto no âmbito escolar e educacional, bem como, na unidade de atendimento socioeducativo, demonstrando sinais de interação e integração dos adolescentes, mesmo que alguns desses adolescentes pertençam a grupos rivais externamente, mas que durante a execução das atividades, demonstraram respeito e momentos de cooperação e aprendizagem. Alves (2014, p.112) reforla que "atividades divertidas e gamificadas podem ser capazes de engajar diferentes públicos e gerações. Este engajamento está diretamente ligado à relevância que o conteúdo tem para as pessoas".

Foi constatado que as relações pessoais e interpessoais sofreram alterações, muitas vezes demonstradas por ações extrovertidas, além de contribuir para um ambiente mais agradável e sociável, sem hostilidade, mesmo por um período temporário. Teixeira e Apresentação (2014, p. 304) explicam que com a utilização de jogos, "o aluno constrói seu conhecimento de maneira ativa e dinâmica e os sujeitos envolvidos estão geralmente mais propícios à ajuda mútua e à análise dos erros e dos acertos, proporcionando uma reflexão em profundidade sobre os conceitos que estão sendo discutidos". Esses momentos oferecem aos docentes as condições necessárias para compreender como está acontecendo o processo de aprendizagem dos seus alunos e a partir deste cenário, dinamizar as relações, inclusive por meio de reflexões sobre as jogadas realizadas pelos jogadores.

A inserção das tecnologias no âmbito educacional pode favorecer a rápida inserção de temas e conteúdo, no desenvolvimento de metodologias de ensino, na aplicabilidade de plataformas de ensino e suas avaliações, mas que sem os cuidados necessários podem substituir de forma gradual e imperceptível as funções do professor, afetando as relações pessoais, interpessoais e intrapessoais, distorcendo o senso crítico, e minimizando sentimentos e emoções.

"Conhecer a cultura, a estrutura social, a idade e os interesses do público ao qual as atividades se destinam, é uma condição imprescindível para a escolha correta 
da atividade, pois permite prever as condições necessárias dentro de cada faixa de desenvolvimento dos estudantes (TEIXEIRA E APRESENTAÇÃO, 2014). Conforme destaca Alves (2014) alguns games podem ter resultados efetivos na instrução em determinada situação, mas que não podem ser relacionados com outros games, ou seja, os resultados poderão ser diferentes.

Cabe destacar também, que foi observado durante as atividades que os adolescentes desenvolveram a percepção, o pensamento crítico, o raciocínio, a imaginação e a criatividade. Essa prática torna também reflexiva a atuação dos demais docentes da escola, pois a escola oferece uma grande quantidade de jogos lúdicos que podem servir como instrumentos mediadores de uma proposta pedagógica e auxiliar na construção de uma metodologia transformadora na perspectiva educacional.

\section{CONSIDERAÇÕES FINAIS}

A prática pedagógica em um ambiente socioeducativo, deve ser abordada pelo docente como uma possibilidade de aplicar metodologias que atendam a adolescentes com atos infracionais, que sofrem por vezes com a desigualdade social e cultural, que são instáveis emocionalmente, imprevisíveis em suas ações e que muitas vezes, a educação não é uma de suas prioridades.

Dessa forma, a prática docente estará voltada para a inclusão, para uma educação inclusiva que tenha condições de além de levar o conhecimento e a educação aos adolescentes em cumprimento de medida socioeducativa, servir como objeto de integração, de interação ampliando as questões emocionais e pessoais, contribuindo para um ambiente acolhedor e tranquilo.

A inclusão compreende a importância e a compreensão das dificuldades de natureza educacional para atender as demandas que surgem perante as dificuldades políticas, sociais e culturais e no reconhecimento do desafio do docente, do ponto de vista pedagógico de definir uma prática que atenda a adolescentes em internação em uma unidade de atendimento socioeducativo e suas realidades vivenciadas.

Realidades que desafiam o cotidiano do educando, mas que, manifestam sua inquietude e transformam-se em instrumentos que reconhecem o conhecimento 
prévio desses adolescentes, o meio aos quais eles vivem, suas realidades, seus relatos que podem funcionar como interlocutores de uma ação reflexiva crítica, contribuindo para uma reconstrução social.

Humanização que destaca o humano, o social, promovendo as mais variadas qualidades das relações pessoais, estabelecendo os vínculos necessários para o processo de adaptação, conhecimento e desenvolvimento de práticas educacionais e de formação, fundamentais para a evolução humana.

AGRADECIMENTOS: ao Centro de Atendimento Socioeducativo, a Escola Estadual de Ensino Médio Humberto de Campos, a Universidade Franciscana. Esse estudo contou com a bolsa PROSUC CAPES.

\section{REFERÊNCIAS}

ALVES, F. Gamification: como criar experiências de aprendizagem engajadoras: um guia completo do conceito à prática. 1.ed. São Paulo: DVS Editora, 2014.

FASE. Fundação de Atendimento Sócio-Educativo do Rio Grande do Sul. Quem somos. Disponível em: https://fase.rs.gov.br/quem-somos. Acesso em: 21 set. 2021.

FREIRE, P. Pedagogia da autonomia: saberes necessários à prática educativa. 59.ed. Rio de Janeiro: Paz e Terra, 2019.

GABRIEL, M. Educar: a (r)evolução digital na educação. São Paulo: Saraiva, 2013.

GUEBERT, M. C. C. Inclusão: uma realidade em discussão. Curitiba: Intersaberes, 2012.

KNOLL, G.F. et. al. Jogos "acidentalmente" educativos: tecnologia e motivação para a aprendizagem. In: DICKMANN, I. (Org.). START: como a gamificação e os jogos de aprendizagem estão transformando a práxis educativa atual com suas dinâmicas inovadoras e criativas Chapecó: Livrologia, 2021.

KNOLL, G.F.; SOARES, M. P.; MOREIRA, G.L.da R. Jogos digitais aplicados ao ensino: de entretenimento a tecnologias de aprendizagem. In: TONETTO, F.; KNOLL, G.F. (Orgs.). Upgrade: jogos, entretenimento e cultura. São Paulo: Pimenta Cultural, 2021. p. 17-27.

MINETTO, M. F. Currículo na educação inclusiva: entendendo esse desafio. 2.ed. Curitiba: Ibpex, 2008. 
MORAN, J. Reinventando as formas de ensinar e de aprender. Educação Transformadora. 3/06/2021. Disponível em: http://www2.eca.usp.br/moran/wpcontent/uploads/2021/06/reinventando.pdf Acesso em: 21 set. 2021.

TEIXEIRA, R. R. P.; APRESENTAÇÃO, K. R. dos S. da. Jogos em sala de aula e seus benefícios para a aprendizagem da matemática. Revista Linhas, Florianópolis, v. 15, n. 28, p. 302-323, jan./jun. 2014.

TEIXEIRA, K. L. O universo lúdico no contexto pedagógico. Curitiba: Intersaberes, 2018. 